\title{
Percepções do cuidador familiar sobre o cuidado prestado ao idoso hospitalizado
}

\section{Family's caregiver perceptions of care given to the hospitalized aged*}

\author{
Bárbara Pires de Andrade Lage Cabral ${ }^{1}$, Ciomara Maria Pérez Nunes ${ }^{2}$
}

http://dx.doi.org/10.11606/issn.2238-6149.v26i1p118-127

Cabral BPAL, Nunes CMP. Percepções do cuidador familiar sobre o cuidado prestado ao idoso hospitalizado. Rev Ter Ocup Univ São Paulo. 2015 jan./abr.;26(1):118-27.

RESUMO: Propõe-se identificar e descrever as percepções de familiares sobre o cuidado ao idoso hospitalizado. É um estudo transversal clínico-qualitativo e a coleta de dados aconteceu em um hospital de urgência e emergência por 30 dias em julho de 2013 , finalizada quando atingiu a saturação das respostas. A coleta de dados se deu por meio de entrevistas semi-estruturadas com aplicação dos seguintes instrumentos: perguntas fechadas para caracterização do perfil sociodemográfico da população; semiabertas para identificar a percepção dos cuidadores familiares sobre o processo de cuidado durante a hospitalização; e aplicação do instrumento Canadian Occupational Performance Measure $(\mathrm{COPM})$ para identificar a percepção dos participantes quanto à importância atribuída às principais atividades que realiza, à sua atuação e à sua satisfação com tal atuação no cuidado ao idoso hospitalizado. A amostra contou com 25 cuidadores familiares que destacaram: sentimentos ambivalentes ao prestar os cuidados; dimensões objetivas e subjetivas do cuidado; vantagens e desvantagens de cuidar em casa e no hospital e reflexões sobre o papel de cuidador. O cuidado ao idoso é uma tarefa complexa, especialmente no contexto hospitalar. Ações voltadas para o cuidador familiar deve ser prática comum das equipes.

DESCRITORES: Idoso; Cuidadores; Hospitalização.
Cabral BPAL, Nunes CMP. Family's caregiver perceptions of care given to the hospitalized aged. Rev Ter Ocup Univ São Paulo. 2015 jan./abr.;26(1):118-27.

ABSTRACT: The aim is to identify and describe the family perceptions of the care given to the hospitalized aged. It is a qualitative cross-clinical study and the data collection took place in a university hospital during 30 days in July 2013, being finalized when the data saturation was achieved. The data collection was performed by semi-structured interview by the instruments: closed questions to characterize the demographic profile of the population and semi-open questions for perception of family caregivers about the process of care during hospitalization; and application of the Canadian Occupational Performance Measure (COPM) to the participants perceptions regarding the importance attached to the main activities carried out, their performance and their satisfaction with such activities in hospitalized elderly care. The sample consisted of 25 family caregivers who highlighted: ambivalent to provide care; objective and subjective dimensions of care; advantages and disadvantages of home care and hospital, and reflections on the role of caregiver. About the COPM, the majority had trouble scoring and analyzing the condition of caregiver. The aged care is a complex task, especially in the hospital setting. Actions for the caregiver must be a common practice by the multidisciplinary team.

KEY WORDS: Aged; Caregivers; Hospitalization.

\footnotetext{
* Manuscrito apresentado como Trabalho de Conclusão de Curso da Residência Integrada Multiprofissional em Saúde do Hospital das Clínicas da Universidade Federal de Minas Gerais, apresentado como requisito parcial para obtenção do título de Residente Multiprofissional em Saúde - área de concentração Saúde do Idoso.

1. Terapeuta Ocupacional, Residente pela Residência Multiprofissional em Saúde do Hospital das Clínicas da Universidade Federal de Minas Gerais, área de concentração Saúde do Idoso. barbarapires@gmail.com

2. Terapeuta Ocupacional, Professora do Departamento de Terapia Ocupacional da Universidade Federal de Minas Gerais. E-mail: ciomara-nunes@ufmg.br
} 


\section{INTRODUÇÃO}

$\mathrm{O}$ crescimento da população idosa no mundo, aliado ao aumento da expectativa de vida e da prevalência de morbidades e comorbidades, pode levar ao maior número de internações hospitalares. Essas, por sua vez, podem fragilizar o idoso e gerar dependência ${ }^{1-2}$.

No ambiente hospitalar, a situação de vulnerabilidade do idoso e sua capacidade de manter as habilidades físicas e mentais necessárias para uma vida independente, podem se agravar, exigindo assistência e cuidados diretos pela equipe de saúde e por seus cuidadores ${ }^{2}$. Fatores como o aumento significativo da população idosa dependente, a dificuldade do Estado em suprir as necessidades de cuidado e aspectos culturais, levam ao surgimento do cuidador informal/ familiar como principal responsável pelos cuidados com o idoso e pela qualidade de vida dessas pessoas ${ }^{2}$.

Cuidador familiar é aquele indivíduo próximo ao idoso que assume o papel de cuidar sem necessidade de contrato, ganho financeiro e sem necessariamente ter uma formação específica ${ }^{3-4}$. As tarefas desempenhadas pelo cuidador são inúmeras, auxiliando os idosos direta ou indiretamente tanto em Atividades de Vida Diária Instrumentais (AIVD) como limpeza da casa e administração financeira, quanto em Atividades Básicas de Vida Diária (ABVD) como banhar e vestir o idoso. Essas tarefas, associadas a condições específicas do idoso, do ambiente e do próprio cuidador podem gerar sobrecarga para o cuidador ${ }^{1,5}$.

Como parceiro da assistência, as necessidades do cuidador familiar e sua percepção sobre o cuidado ao idoso são relevantes para a implementação de práticas e estratégias de cuidados pela equipe multiprofissional durante todo o percurso do idoso na internação, inclusive na preparação da alta ${ }^{3,6}$. Sendo assim, a interação entre cuidador e equipe multiprofissional de saúde favorece a possibilidade de se alcançar a longitudinalidade e a integralidade do cuidado no contexto da gerontologia, uma vez que o cuidador contribui para identificação de necessidades de atenção da pessoa que está sendo cuidada.

O objetivo primário do estudo é identificar e descrever as percepções de cuidadores familiares sobre o cuidado que prestam ao idoso hospitalizado. Os objetivos secundários são: obter informações sobre qual o significado de cuidar e como o cuidador se sente desempenhando essa tarefa; e identificar qual é o grau de importância atribuído pelo cuidador às principais atividades relacionadas ao cuidado.

\section{METODOLOGIA}

Trata-se de um estudo transversal clínico-qualitativo que permite ao pesquisador acolher os sentimentos dos sujeitos pesquisados, em atitude clínica, "com olhos e ouvidos qualificados para compreender existencialmente os sofrimentos que acometem o outro" (p. 239)7. A pesquisa qualitativa estuda uma tentativa de interpretar os fenômenos em termos de significados que as pessoas atribuem a eles, pretende conhecer a fundo suas vivências e que representações elas têm dessas experiências ${ }^{8}$. $\mathrm{O}$ método clínico-qualitativo é considerado como um refinamento dos métodos qualitativos gerais das ciências humanas, sendo aqui aplicado a uma forma específica de cuidado que integra àquele prestado no contexto hospitalar.

O estudo desenvolveu-se no Hospital Risoleta Tolentino Neves em Belo Horizonte, que atende em regime de urgência e emergência, nas seguintes unidades de cuidado: Unidade de Acidente Vascular Cerebral (UAVC), Equipe de Cuidados Paliativos (ECP), Pronto Atendimento (PA), Clínica Médica (CM) e Equipe Volante (EV) - que atende idosos que sofreram fratura de quadril ou possuem insuficiência vascular periférica. A população alvo do estudo compreendeu cuidadores familiares primários que não recebiam remuneração para o cuidado de idosos hospitalizados nessas unidades.

Os idosos eram atendidos por profissionais do hospital e por residentes da Residência Integrada Multiprofissional em Saúde do Hospital das Clínicas da Universidade Federal de Minas Gerais, área de concentração em saúde do idoso.

Os cuidadores dos idosos foram selecionados a partir uma lista de pacientes atualizada diariamente pelos residentes de terapia ocupacional. A amostra foi de conveniência. Foram excluídos da amostra os cuidadores formais e aqueles informais que não eram cuidadores primários ou que não foram encontrados próximos ao leito durante o período em que a pesquisadora realizou a busca ativa. Salienta-se que estes cuidadores podiam permanecer no hospital em tempo integral, conforme assegurado no Estatuto do Idoso'.

Ressalta-se que a pesquisadora fazia parte da equipe de residentes, porém não atendia os idosos durante o período de coleta de dados.

A coleta dos dados iniciou-se em julho de 2013 e durou 30 dias, quando as entrevistas foram conduzidas individualmente e em ambiente privado. Os instrumentos utilizados foram: perguntas fechadas para caracterização sociodemográfica da população; perguntas semi-estruturadas para conhecer a percepção dos cuidadores sobre o cuidado prestado ao idoso hospitalizado, e a aplicação da Canadian 
Occupational Performance Measuare (COPM), ou Medida de Desempenho Ocupacional Canadense. A coleta foi encerrada após atingir a saturação dos dados da entrevista semi-estruturada sobre a percepção do cuidador familiar em relação ao cuidado.

Foram contatados, através da lista de pacientes atualizada diariamente pelos residentes de terapia ocupacional, 30 cuidadores, porém dois foram excluídos por não estar próximos ao leito durante a busca ativa da pesquisadora, um por ser cuidador formal e dois por serem cuidadores secundários ou terciários. Assim, o estudo contou com a participação de 25 cuidadores familiares primários e não houve recusa para participar da pesquisa.

O projeto foi aprovado pelo Comitê de Ética em Pesquisa/UFMG - parecer $n^{\circ}: 377 / 2011$, CAAE 03770 203000 11. Os objetivos e os procedimentos do estudo foram explicados aos participantes que, ao concordarem com a participação voluntária, assinaram o Termo de Consentimento Livre e Esclarecido (TCLE).

Para a caracterização sociodemográfica dos idosos foi realizada entrevista com perguntas fechadas para registro dos dados referentes à idade, sexo, estado civil, escolaridade, região de residência, motivo da internação hospitalar, com quem residia antes da internação e com quem irá morar após a alta. Essas informações foram fornecidas pelos idosos e, no caso de idosos não respondentes, as informações foram dadas pelos cuidadores. Para caracterização dos cuidadores foi utilizado também instrumento com perguntas fechadas para registro dos dados sociodemográficos como: idade, sexo, estado civil, escolaridade, há quanto tempo é o cuidador, grau de parentesco com o idoso, quantas horas por dia despende na tarefa de cuidar e se tem ajuda para o cuidado. No caso específico da ajuda que o cuidador recebe, foi detalhado qual o tipo de ajuda: financeira, cuidados diretos compartilhados com outras pessoas e/ou orientação, formação ou treinamento específico para a administração dos cuidados ao idoso hospitalizado.

A seguir foi feita uma entrevista que contemplou aspectos subjetivos do cuidado com perguntas semiabertas sobre o significado de cuidar do familiar idoso e como o cuidador se sente realizando essa tarefa. Após as entrevistas foi aplicado a $C O P M^{10}$ visando identificar a percepção do cuidador familiar quanto à importância atribuída às principais atividades que realiza, à sua atuação como cuidador e à sua satisfação com tal atuação no cuidado ao idoso sob sua responsabilidade no ambiente hospitalar. Esse instrumento de medida é específico da Terapia Ocupacional, criado com o objetivo de detectar mudanças na autopercepção em relação à performance e à satisfação do cliente ao realizar tais atividades, no formato de uma entrevista semi-estruturada. Pode ser utilizado para identificar áreas-problemas e quantificar as prioridades de desempenho ocupacional e da satisfação do cliente ${ }^{10}$.

Neste estudo, a administração da COPM foi dividida em quatro etapas ${ }^{11}$. A primeira etapa foi baseada na definição do problema do cuidador relacionado ao seu desempenho ocupacional, priorizando a identificação de tarefas que o participante realiza para o idoso durante a internação. Identificados os problemas, o cuidador familiar foi solicitado a quantificar essas atividades por grau de importância em sua vida, sendo pontuadas a partir de escala que varia de um a dez pontos ${ }^{11}$. Selecionadas as cinco tarefas de maior importância, nas terceira e quarta etapas, os participantes foram solicitados a fazer uma autoavaliação do desempenho atual e da satisfação com tal desempenho em cada tarefa, atribuindo pontos de 0 a 10: o escore 10 indica "capaz de fazer extremamente bem" e o escore 1 "incapaz de fazer" na avaliação do desempenho e, na avaliação da satisfação, 10 indica 'extremamente satisfeito' e o escore 1 'nada satisfeito'. É reportada confiabilidade adequada teste reteste para os escores de desempenho $(\mathrm{r}=.89, \mathrm{p}<.001)$ e satisfação $(\mathrm{r}=.88, \mathrm{p}<.001)^{11}$.

Todo o processo de entrevista foi gravado e, em seguida, transcrito e analisado individualmente pela pesquisadora. Para a análise das perguntas semi-abertas relativas à percepção dos familiares acerca do processo de cuidado durante a hospitalização, foi utilizada a análise de conteúdo temática, por essa consistir em descobrir os núcleos de sentido que compõem uma comunicação cuja presença ou frequência tenham significado para o objetivo do estudo ${ }^{7}$. É utilizado o raciocínio indutivo que permite a identificação dos conteúdos associados às respostas dos entrevistados. Os conteúdos assim identificados podem, então, ser interpretados de forma a gerar conceitos, eventualmente capazes de serem generalizados para outros contextos ${ }^{8}$.

Os dados sóciodemográficos dos idosos e dos cuidadores e os dados de desempenho e satisfação coletados pela COPM foram analisados descritivamente pela frequência de ocorrência das respostas, com média e frequência relativa, e desvio padrão para variável idade, por meio da planilha eletrônica Microsoft Excel 2007 para Windows XP/Vista.

\section{RESULTADOS}

\section{Características sociodemográficas}

As características sociodemográficas dos idosos estão descritas na Tabela 1. 
Cabral BPAL, Nunes CMP. Percepções do cuidador familiar sobre o cuidado. Rev Ter Ocup Univ São Paulo. 2015 jan./abr.;26(1):118-27.

Tabela 1 - Características sociodemográficas dos idosos hospitalizados

\begin{tabular}{|c|c|c|c|}
\hline & Características Demográficas & $\mathrm{n}=\mathbf{2 5}$ & $\%$ \\
\hline \multirow{2}{*}{ Gênero } & Feminino & 8 & 36 \\
\hline & Masculino & 16 & 64 \\
\hline Idade & Idade Média, Desvio Padrão (DP) & 76 anos $\pm 8,7$ & \\
\hline \multirow{4}{*}{ Estado Civil } & Solteiro(a) & 2 & 8 \\
\hline & Casado(a) & 9 & 36 \\
\hline & Viúvo(a) & 11 & 44 \\
\hline & Divorciado(a) & 3 & 12 \\
\hline \multirow{4}{*}{ Escolaridade } & Analfabetos & 11 & 44 \\
\hline & $1^{\text {a }}$ a $4^{\mathrm{a}}$ série & 10 & 40 \\
\hline & $5^{\mathrm{a}}$ a $8^{\mathrm{a}}$ série & 3 & 12 \\
\hline & Segundo Grau Completo & 1 & 4 \\
\hline \multirow{8}{*}{ Como reside } & Sozinho(a) & 2 & 8 \\
\hline & ILPI & 1 & 4 \\
\hline & Cônjuge e filhos & 8 & 32 \\
\hline & Filhos & 4 & 16 \\
\hline & Filhos, nora/genro e/ou netos & 4 & 16 \\
\hline & Filhos e netos & 4 & 16 \\
\hline & Mãe e irmãos & 1 & 4 \\
\hline & Irmã e sobrinho & 1 & 4 \\
\hline \multirow{2}{*}{$\begin{array}{l}\text { Moradia pós } \\
\text { hospitalização }\end{array}$} & Continuará morando no mesmo local & 21 & 84 \\
\hline & Não continuará morando no mesmo local & 4 & 16 \\
\hline \multirow{7}{*}{$\begin{array}{l}\text { Motivo da } \\
\text { internação } \\
\text { hospitalar }\end{array}$} & AVE & 13 & 52 \\
\hline & Condições clínicas instáveis (pneumonia, infecção urinária) & 2 & 8 \\
\hline & Amputação de membros inferiores & 2 & 8 \\
\hline & Fratura de membros inferiores & 4 & 16 \\
\hline & Pé diabético & 2 & 8 \\
\hline & Perda súbita dos movimentos & 1 & 4 \\
\hline & Infecção de feridas & 1 & 4 \\
\hline
\end{tabular}

Conforme disposto acima, os idosos eram $64 \%$ do sexo masculino, com idade média de 76 anos com desvio padrão de 8,7 . Sobre o estado civil, $44 \%$ eram viúvos, seguidos por casados, divorciados e solteiros. A maior parte residia com algum familiar, apenas dois moravam sozinhos e um em uma Instituição de Longa Permanência para Idosos (ILPI). Essas informações podem estar relacionadas com parte considerável dos cuidadores serem filhos ou cônjuge e também com a perspectiva dos idosos de continuar morando no mesmo local que residiam antes da hospitalização. Os idosos que provavelmente mudariam de residência foram aqueles que moravam sozinhos, em ILPI ou com irmãos e sobrinhos.

Pouco menos da metade, 44\%, eram analfabetos e outros $40 \%$ tinham até a quarta série. Sobre a internação, $36 \%$ estavam na ECP, $32 \%$ na UAVC, $20 \%$ na EV, $8 \%$ no PA e $4 \%$ na CM.

A Tabela 2 descreve os dados sociodemográficos dos cuidadores familiares participantes. 
Tabela 2 - Características sociodemográficas dos cuidadores familiares

\begin{tabular}{|c|c|c|c|}
\hline & Características demográficas & $\mathbf{n}=\mathbf{2 5}$ & $\%$ \\
\hline \multirow{2}{*}{ Gênero } & Feminino & 18 & 72 \\
\hline & Masculino & 7 & 28 \\
\hline Idade & Idade Média, Desvio Padrão (DP) & 47 anos $\pm 7,5$ & \\
\hline \multirow{4}{*}{ Estado civil } & Solteiro(a) & 2 & 8 \\
\hline & Casado(a) & 9 & 36 \\
\hline & Viúvo(a) & 11 & 44 \\
\hline & Divorciado(a) & 3 & 12 \\
\hline \multirow{5}{*}{ Escolaridade } & Analfabetos & 1 & 4 \\
\hline & $1^{\mathrm{a}}$ a $4^{\mathrm{a}}$ série & 7 & 28 \\
\hline & $5^{\mathrm{a}}$ a $8^{\mathrm{a}}$ série & 7 & 28 \\
\hline & Segundo Grau Completo & 9 & 36 \\
\hline & Ensino Técnico & 1 & 4 \\
\hline \multirow{6}{*}{ Vínculo } & Cônjuge & 4 & 16 \\
\hline & Filho(a) & 14 & 56 \\
\hline & Irmão(a) & 3 & 12 \\
\hline & Nora & 1 & 4 \\
\hline & Genro & 1 & 4 \\
\hline & Sobrinha & 1 & \\
\hline \multirow{6}{*}{$\begin{array}{l}\text { Experiência como } \\
\text { cuidador }\end{array}$} & Após internação do idoso & 13 & 52 \\
\hline & Até 01 ano & 4 & 16 \\
\hline & Entre 02 a 05 anos & 3 & 12 \\
\hline & Entre 05 a 10 anos & 2 & 8 \\
\hline & Acima de 10 anos & 2 & 8 \\
\hline & Não se considera cuidador & 1 & 4 \\
\hline \multirow{3}{*}{$\begin{array}{l}\text { Tempo com o } \\
\text { cuidado ao idoso }\end{array}$} & Despende até 6 horas & 7 & 28 \\
\hline & Despende de 06 à 12 horas & 7 & 28 \\
\hline & Despende de 12 à 24 horas & 11 & 44 \\
\hline \multirow{3}{*}{$\begin{array}{l}\text { Ajuda para o } \\
\text { cuidado ao idoso }\end{array}$} & Recebe ajuda constante & 16 & 64 \\
\hline & Recebe ajuda quando solicita ou esporadicamente & 3 & 12 \\
\hline & Não recebe ajuda & 6 & 24 \\
\hline \multirow{2}{*}{$\begin{array}{l}\text { Natureza da ajuda } \\
\text { no cuidado }\end{array}$} & Ajuda através de cuidados diretos com o idoso & 18 & 95 \\
\hline & Ajuda financeira & 1 & 5 \\
\hline
\end{tabular}

Conforme disposto acima, a maioria era do sexo feminino, com idade média de 47 anos, com um desvio padrão de 7,5. A maior parte estudou até a $8^{\mathrm{a}}$ série do primeiro grau e $36 \%$ completaram o ensino médio. Mais da metade, $56 \%$, eram filhos dos idosos, seguidos por cônjuge e irmãos. A maioria despendia entre 12 a 24 horas no hospital junto ao idoso e $76 \%$ recebia ajuda de outras pessoas, sendo que $95 \%$ na forma de auxílio nos cuidados diretos. Ou seja, os cuidadores primários costumavam revezar com outros familiares durante a internação. Enfatiza-se que os cuidados diretos, quando realizados pelos familiares, são supervisionados e/ou treinados pelos profissionais do hospital. 


\section{Percepções dos cuidadores familiares sobre o processo de cuidado ao idoso hospitalizado}

Nesta pesquisa foi possível observar que muitos cuidadores percebem o cuidar como algo natural ou uma obrigação.

"Ele é meu esposo, eu casei com ele. Eu tenho que cuidar." (Cuidadora 14).

Alguns acreditam que ao negligenciarem seu próprio cuidado para cuidar do outro serão recompensados de alguma maneira ou serão reconhecidos por contribuir no cuidado prestado, o que permite inferir uma intencionalidade do ato por trás do fazer, embora, muitas vezes, inconsciente.

"Tudo o que eu faço é querendo talvez que ele fale: obrigada, você me ajudou'”. (Cuidadora 12).

Além disso, essa anulação para cuidar do outro, pode trazer sofrimentos ao cuidador, o que interfere em sua qualidade de vida e também na qualidade do cuidado prestado. Neste sentido, os cuidadores afirmam sentir estresse e sobrecarga durante o processo de cuidar.

"Eu tive que parar de trabalhar pra poder cuidar dela. Por exemplo, hoje eu vou ficar aqui o dia todo [...] Minha vida está em prol dela neste momento." (Cuidadora 05).

Porém, apesar da sobrecarga que impacta negativamente a qualidade de vida do cuidador foi observado nesta pesquisa uma ambivalência de sentimentos gerados pela situação de cuidado. Ficou evidente nas falas dos entrevistados que cuidar é um modo que os cuidadores encontram de retribuir os sentimentos de amor, carinho e cuidado que o idoso teve com eles ao longo da vida.

"É uma obrigação, uma gratidão. Ele sempre foi um bom marido, um companheiro. Eu tive câncer de mama e ele cuidou de mim." (Cuidadora 12).

O cuidar é visto também como modo de aliviar a culpa sentida devido ao processo de adoecimento da pessoa, como o cumprimento de dever para com o outro e uma tentativa de demonstrar que fez o melhor que podia para auxiliar o doente.

"Estou fazendo meu melhor. Como eu olhei minha mãe quando ela precisou, agora com meu pai também não tenho remorso nenhum." (Cuidador 19).

Assim, prevalece a ambivalência dos sentimentos, que oscila entre a culpa por não conseguir cuidar do familiar como gostaria ou estar presente o tempo todo, e o desejo de poder cuidar de si e retomar atividades significativas.

"Eu quero ajudar todo mundo, mas não consigo. Tem a família toda pra eu cuidar. É muita coisa. Eu aguento. Isso me fortalece, só que tem horas que dá vontade de chorar." (Cuidadora 09).

Os cuidadores apontaram também para dimensões objetivas e subjetivas do cuidado. Assim, demonstraram diferenciar cuidados objetivos, como dar banho, vestir e oferecer alimento, e subjetivos, como amor, carinho e companhia.

A "presença" foi uma tarefa descrita mais pelos cuidadores de idosos que estavam na ECP. É possível inferir que este aspecto seja decorrente da vivência de uma situação que coloca o cuidador em proximidade com o fim da vida. Nesse contexto, eles referem um aumento da sensação de impotência na realização dos cuidados diretos, tais como banho, vestir e alimentar, na medida em que percebem que, ainda que desempenhem tarefas relacionadas a esses cuidados, tal fato não repercute em melhora evidente do estado de saúde geral do idoso. Tal percepção impacta negativamente na prestação desses cuidados, que acaba se restringindo.

"É uma impotência, você faz a sua parte, mas percebe que o corpo fica mais debilitado [...] Todos esses cuidados se nós não estivéssemos a enfermagem faria, mas o amor, o cuidado, a atenção faz diferença" (Cuidadora 17).

Já sobre os cuidados objetivos, as tarefas mais importantes desempenhadas pelos cuidadores foram banho, vestir e mudanças de decúbito. Na prestação destes cuidados se destaca o sentimento de constrangimento do cuidador familiar, associado a tarefas de natureza mais íntima, como banho, trocar fraldas e vestir.

"Eu acho que ela fica constrangida [...] tanto que na hora de trocar ela fica contraida. O que me incomoda é que ela tem filhas mulheres e ninguém ajuda. E eu fico constrangido." (Cuidador 10).

Os cuidadores também afirmam que, apesar de não saberem como desempenhar de um modo técnico as tarefas relacionadas aos cuidados objetivos, tentam fazê-las da melhor maneira possível. Como aponta a fala abaixo, o cuidador sente-se satisfeito por perceber que consegue desempenhar as tarefas, as quais à princípio não sente ter capacidade para execução. 
"Me dá satisfação ajudar a virá-lo de posição, porque o que for pra deixar ele bem é o que vai me satisfazer e eu vou tentar fazer o melhor. Fico muito satisfeita, porque quando você vê, você pensa 'nossa, eu nunca vou conseguir fazer' e vê que consegue." (Cuidadora 04).

Em relação ainda aos cuidados objetivos, alguns apontaram para a importância do cuidador auxiliar nas tarefas que o idoso apresente dificuldade, porém promovendo ou mantendo o máximo possível sua independência.

"Eu tento colocar ele pra frente, fazer por ele não! porque vai causar dependência em uma pessoa. Se ele deixa de fazer a barba, vai deixar de abrir e fechar os dedos, vai deixar de sentir o próprio rosto." (Cuidador 07 ).

Porém ainda que os cuidadores auxiliem no cuidado no período em que o idoso permanece no hospital, referiram que cuidar neste contexto faz com que se sintam mais seguros, acolhidos e menos sobrecarregados do que no domicílio:
"Os profissionais sempre tiveram atenção comigo, eu estou aqui tem muito tempo, as pessoas vão nos acompanhando. Aqui eu estou dividindo com uma cuidadora à noite e tem a enfermagem para me ajudar. Mas em casa eram 24 horas e eu, não tinha ajuda nenhuma." (Cuidadora 12).

Em contrapartida, outros apontam para a maior proximidade do idoso com a família ao ficar em casa e, assim, a possibilidade de outras pessoas para auxiliá-los no cuidado.

"O lado positivo é que ele vai estar em um ambiente diferente, ele vai ter um apoio a mais da família. Em casa ele vai ter um número maior de visitas." (Cuidador 24).

\section{Medida de Desempenho Ocupacional Canadense}

Ao responder a COPM quanto às tarefas do cuidar, os cuidadores relataram com mais frequência auxiliar os idosos em: banho, fazer companhia e mudanças de decúbito. A íntegra das tarefas citadas pode ser observada na Tabela 3.

Tabela 3 - Tarefas desempenhadas pelos cuidadores familiares dos idosos hospitalizados

\begin{tabular}{|c|c|c|}
\hline Problemas de desempenho ocupacional & Frequência absoluta & Frequência relativa (\%) \\
\hline Auxiliar no banho & 20 & 23 \\
\hline Auxiliar técnicos de enfermagem & 5 & 6 \\
\hline Compras (higiene pessoal e crédito no celular) & 1 & 1 \\
\hline Controle de finanças & 3 & 3 \\
\hline Alimentar & 7 & 8 \\
\hline Fazer a barba & 2 & 2 \\
\hline Fazer companhia & 11 & 13 \\
\hline Fazer exercícios no idoso & 5 & 6 \\
\hline Higiene oral & 5 & 6 \\
\hline Levar o coletor de urina até o idoso & 1 & 1 \\
\hline Mudança de decúbito & 11 & 13 \\
\hline Oferecer conforto & 1 & 1 \\
\hline Hidratar a pele & 1 & 1 \\
\hline Trocar fraldas & 3 & 3 \\
\hline Verificar uso de medicação & 2 & 2 \\
\hline Vestir & 8 & 9 \\
\hline TOTAL & 86 & 100 \\
\hline
\end{tabular}

A média das respostas fornecidas quanto à importância de auxiliar o idoso nas tarefas durante a internação foi de 9 , com desvio padrão de 1,4 . Sobre o desempenho e a satisfação, a média das notas foi de 8 , com 
desvio padrão de 2,1 e de 2,3 respectivamente.

\section{DISCUSSÃO}

Os homens, comparando-se às mulheres, procuram pouco os serviços de saúde para prevenção de doenças, recorrendo aos serviços, muitas vezes, já em uma fase avançada da doença ${ }^{12}$, o que pode explicar o maior número de internações hospitalares por esse grupo populacional. $\mathrm{O}$ estudo de Gratão et al. ${ }^{13}$, mostrou que o arranjo domiciliar dos idosos que possuiam cuidador familiar era composto por multigerações, no qual residiam cônjuges, filhos, genros e noras, o que vai ao encontro dos dados apurados neste estudo. Na meia idade, fase na qual se encontram os cuidadores desse estudo, espera-se que o adulto comece a ter uma atenção maior com a sua saúde, o que nem sempre é fácil para os indivíduos que são cuidadores já que, muitas vezes, precisam abrir mão do cuidado de si para cuidado do outro $^{14-15}$. Isso requer do profissional de saúde habilidades importantes para abordar o cuidador, como atenção e capacidade de criar um ambiente que propicie sua expressão.

No estudo de Batista e Crispim ${ }^{16}$ também foi possível observar que a maior parte dos cuidadores é um familiar próximo que se reveza com outros durante a hospitalização para não se sobrecarregar, conforme o que foi apurado nesta pesquisa.

Os cuidadores familiares referem ambivalência de sentimentos e sobrecarga ao prestar o cuidado aos idosos hospitalizados. Em um estudo com esposas de pacientes que sofreram Acidente Vascular Encefálico (AVE) ${ }^{17}$, identificou-se o impacto da mudança de seus papéis e de seus maridos, que antes eram ativos, tomavam decisões e, após o adoecimento, ficaram totalmente dependentes, o que aumenta a sensação de sobrecarga e de solidão devido à ausência física e/ou emocional do cônjuge e à dificuldade de retomar as atividades de lazer que antes eram comuns ao casal. Outro artigo ${ }^{4}$ aborda a repercussão do cuidar nas atividades de lazer dos cuidadores informais e demonstra que a maior parte negligencia ou reduz drasticamente a participação nessas atividades devido às inúmeras responsabilidades advindas do cuidado com seu familiar. Os cuidadores, em sua maioria, só vislumbram a retomada do lazer com a morte do idoso.

De acordo com a literatura ${ }^{14}$, o estresse aparece principalmente quando se trata de cuidador único, especialmente quando exerce o cuidado por tempo prolongado, com imposição da tarefa de cuidar e com acúmulo de fatores estressores, como o isolamento e a abdicação de papéis sociais. Aliado ao estresse, o fato de o idoso requerer cuidados básicos contínuos e o adoecimento do próprio cuidador, dificultam a tarefa de cuidar do outro ${ }^{4,14}$. A maior parte dos artigos analisados no estudo de Oliveira e D'Elboux ${ }^{14}$ relata que, independente do nível de cansaço ou estresse, os cuidadores afirmam se sentirem satisfeitos por auxiliar o idoso. Isto porque coexistem na situação de cuidado sentimentos ambivalentes que se relacionam tanto com a sobrecarga decorrente das tarefas, quanto com sentimentos de amor, empatia e gratidão ${ }^{14,18}$.

Outro aspecto identificado neste estudo e confirmado pela literatura é que em casos de pacientes terminais, o cuidador acaba se aproximando mais do idoso e os vínculos são estreitados, aumentando sentimentos de compaixão e solidariedade ${ }^{19}$.

Outro sentimento identificado é o de constrangimento durante a realização de cuidados objetivos. Neste estudo apesar de muitos cuidadores tentarem superar a barreira do pudor, certo tabu limita e pode até impedir a realização de cuidados básicos. Em um estudo conduzido com idosos institucionalizado ${ }^{20}$ revelam que as atividades como banho e vestir ficaram comprometidas para boa parte dos idosos avaliados e a maior repercussão da dependência nessas atividades foi de constrangimento ao expor o corpo.

O cuidador pode tender a não falar de seus sentimentos e, assim, pode agravar seu sofrimento e sensação de sobrecarga. Isto porque o cuidar é considerado parte da cultura brasileira e a maioria dos cuidadores vê o cuidado como algo natural da vida, uma obrigação e não uma opção ou escolha ${ }^{18}$. Tal aspecto deve constantemente ser observado pela equipe.

Outro aspecto identificado neste estudo se relaciona ao período da alta hospitalar. Ao retornar para casa, a visão do cuidado é diferente daquela no hospital, ocorrendo o que Rodrigues et al. ${ }^{18}$ chamam de "passagem do curar para o processo de cuidar em casa" (p.3) e, nessa transição, o cuidado acontecerá de acordo com a cultura, tanto da sociedade na qual o idoso está inserido quanto da família, uma vez que cada uma irá construir o conceito de cuidado $^{18}$. Por outro lado, alguns cuidadores, tanto neste trabalho quanto na literatura ${ }^{18}$, acreditam que, em casa, o idoso terá mais conforto e os cuidadores mais facilidade para conciliarem as tarefas do dia-a-dia. Mesmo assim, temem que, caso o idoso vá para casa, ele tenha uma piora do quadro clínico e possa morrer. Acreditam que, caso a piora ocorra no hospital, a morte poderia ser evitada ou postergada por receberem mais prontamente cuidados de maior complexidade do que os prestados no domicílio.

Rodrigues et al. ${ }^{18}$ afirmam que a equipe de saúde transfere a responsabilidade do cuidado para a família sem prepará-la para fazê-lo ou fornecer algum tipo de suporte, o que pode explicar parte do medo que os cuidadores 
tem em levar o idoso para casa e a ideia de que qualquer eventualidade será de sua inteira responsabilidade. $\mathrm{O}$ estudo de Lovat et al. ${ }^{21}$ corrobora com esse dado, apontando que a maior parte dos cuidadores não veem os profissionais da saúde como aliados no cuidado e gostariam de ter maior participação nesse processo para se sentirem mais seguros após a alta. Assim, a transição para o processo de alta deve ser feita com atenção e delicadeza. A equipe deve compreender o meio em que vive o idoso e seus familiares para tornar esse processo o menos doloroso possível. A atenção da equipe contribuirá para que a família não a veja como detentora de todo poder sobre a saúde do paciente.

Reitera-se a relevância de orientações prestadas pela equipe com esta finalidade, inclusive porque observou-se que parte dos cuidadores deste estudo buscam desenvolver a independência do paciente, o que é algo que contribui significativamente para o processo de recuperação ou manutenção da funcionalidade.

Com a aplicação da COPM, as respostas obtidas estão de acordo com a revisão integrativa da literatura feita por Oliveira e D'Elboux ${ }^{14}$. O cuidar, na maior parte das vezes, é mais um dos múltiplos papéis assumidos pela mulher, sendo essa uma tarefa repassada de geração para geração e, por isso, acaba sendo compreendida como natural e inevitável ${ }^{13-14}$.

Ressalta-se que, neste estudo, a escolaridade influenciou na compreensão e classificação da COPM, sendo observado que os cuidadores com maior escolaridade apresentaram maior facilidade em pontuar e analisar criticamente a condição de cuidador. Vale enfatizar que a escolaridade dos cuidadores é uma informação relevante, uma vez que são eles que receberão as orientações da

\section{REFERÊNCIAS}

1. Rocha BMP, Pacheco JEP. Idosos em situação de dependência: estresse e coping do cuidador informal. Acta Paulista Enferm. 2013;26(1):50-6. doi: http://dx.doi.org/10.1590/S010321002013000100009 .

2. Mendes J, Maftum MA, Lacerda MR, Mantovani MF. Percepção das enfermeiras sobre a presença do acompanhante na internação hospitalar do idoso. Cogitare Enferm. 2010;15(3):448-53. doi: http://dx.doi.org/10.5380/ ce.v15i3.18886.

3. Rafacho M, Oliver FC. A atenção aos cuidadores informais/ familiares e a estratégia de Saúde da Família: contribuições de uma revisão bibliográfica. Rev Ter Ocup Univ São Paulo. equipe de saúde e para quem as abordagens de educação em saúde serão praticadas. É necessário que o profissional utilize diferentes estratégias de linguagem condizentes com a compreensão de cada indivíduo abordado.

\section{CONCLUSÕES}

Considerando os achados deste estudo pode-se confirmar a natureza complexa do cuidado. Ficou evidente a importância do acolhimento do cuidador pela equipe multidisciplinar por meio de espaços de escuta nos quais possa falar de suas experiências e dificuldades no cotidiano do cuidado.

Identificou-se o receio de alguns cuidadores, no momento da alta, relacionado à sua percepção da dificuldade de acesso a cuidados de longo prazo aos idosos. Neste sentido, o presente estudo aponta para a importância da atenção ao idoso de forma integral, como uma linha de cuidados que articule serviços de referência e contrarreferência.

Como limitações do estudo, pode-se apontar a falta de dados sobre a funcionalidade dos idosos, que poderiam se relacionar com outros apresentados, como a necessidade de um cuidador e o grau de dependência. Porém acredita-se que os dados deste estudo podem se constituir como referência para ações em terapia ocupacional na atenção a cuidadores familiares de idosos no contexto hospitalar.

Sugere-se que os profissionais, especialmente aqueles que atuam no cenário de internação, realizem intervenções que visem minimizar os impactos da tarefa de cuidar e, consequentemente, melhora da qualidade de vida do idoso e de seus cuidadores familiares no ambiente hospitalar.
2010;21(1):41-50. doi: http://dx.doi.org/10.11606/issn.22386149.v21i1p41-50.

4. Batista MPP, Micas FL, Forattore FS, Almeida MHM, Couto TV. Repercussões do papel de cuidador nas atividades de lazer de cuidadores informais de idosos dependentes. Rev Ter Ocup Univ São Paulo. 2012;23(2):186-92. doi: http://dx.doi. org/10.11606/issn.2238-6149.v23i2p186-192.

5. Pereira MG, Carvalho H. Qualidade vida, sobrecarga, suporte social, ajustamento conjugal e morbidade psicológica em cuidadores de idosos com dependência funcional. Temas Psicol. 2012;20(2):369-84. doi: http://dx.doi.org/10.9788/ TP2012.2-07. 
6. Besse A, Weber LP, Rolim RA. Atenção ao idoso em unidades de internação: o enfoque da terapia ocupacional. In: Domingues MA, Lemos ND. Gerontologia: os desafios nos diversos cenários da atenção. São Paulo: Manole; 2010.

7. Turato ER. Tratado da metodologia da pesquisa clínicoqualitativa: construção teórico-epistemológica, discussão comparada e aplicação nas áreas da saúde e humanas. Petrópolis: Vozes; 2003.

8. Turato ER. Métodos qualitativos e quantitativos na área da saúde: definições, diferenças e seus objetivos de pesquisa. Rev Saúde Pública. 2005;39(3):507-14. doi: http://dx.doi. org/10.1590/S0034-89102005000300025.

9. Brasil. Estatuto do idoso: lei federal $\mathrm{n}^{\mathrm{o}} 10.741$, de 01 de outubro de 2003. Brasília, DF: Secretaria Especial dos Direitos Humanos; 2004. Disponível em: http://portal. mj.gov.br/sedh/ct/cndi/estatuto1.htm.

10. Law M, Baptiste S, Carswell A, McColl MA, Polatajko H, Pollock N. Medida Canadense de Desempenho Ocupacional (COPM). Org. Trad. de Magalhães L, Magalhães LC, Magalhães LV, Cardoso AA. Belo Horizonte: Ed. UFMG; 2009.

11. Cup EH, Scholte OP, Reimer WJ, Thijssen MC, Van Kuyk-Minis MA. Reliability and validity of the Canadian Occupational Performance Measure in stroke patients. Clin Rehabil. 2003;17(4):402-9. doi: 10.1191/0269215503cr635oa.

12. Borges HA, Vargas DBM. As dificuldades encontradas pelo idoso hospitalizado sem acompanhante. Rev Científica ITPAC (Araguaína). 2013;4(3). Disponível em: http://www.itpac.br/ hotsite/revista/artigos/43/6.pdf.

13. Gratão ACM, Talmelli LFS, Figueiredo LC, Rosset I, Freitas CP, Rodrigues RAP. Dependência funcional de idosos e a sobrecarga do cuidador. Rev Esc Enferm USP. 2013;47(1):137-44. doi: http://dx.doi.org/10.1590/S008062342013000100017 .

14. Oliveira DC, D’Elboux MJ. Estudos nacionais sobre cuidadores familiares de idosos: revisão integrativa. Rev Bras
Enferm. 2012;65(5):829-38. doi: http://dx.doi.org/10.1590/ S0034-71672012000500017

15. Duarte YAO, Diogo MJD. Cuidados em domicílio: conceitos e práticas. In: Freitas EV, PY L. Tratado de geriatria e gerontologia. 3a ed. Rio de Janeiro: Guanabara Koogan; 2011. p.1276-84.

16. Batista NC, Crispim NF. A interferência das relações familiares no processo de envelhecimento: um enfoque no idoso hospitalizado. Rev Kairós Gerontol. 2012;15(5):16989. Disponível em: http://revistas.pucsp.br/index.php/kairos/ article/view/10254/11436.

17. McCarthy MJ. Identifying modifiable factors associated with depression across the lifespan in stroke survivor-spouse dyads; paper 171 [Dissertations and Theses]. Portland: Portland State University; 2011. Available from: http://pdxscholar.library. $\mathrm{pdx}$. edu/cgi/viewcontent.cgi?article $=1170 \&$ context $=$ open access_etds.

18. Rodrigues RAP, Marques S, Kusumota L, Santos EB, Fhon JRS, Fabrício-Wehbe SCC. Transição do cuidado com o idoso após acidente vascular cerebral do hospital para casa. Rev Latino-Am Enferm. 2013;21(Spec):216-24. doi: http:// dx.doi.org/10.1590/S0104-11692013000700027

19. Inocenti A, Rodrigues IG, Miasso AI. Vivências e sentimentos do cuidador familiar do paciente oncológico em cuidados paliativos. Rev Eletrônica Enferm. 2009;11(4):858-65. Disponível em: http://www.fen.ufg.br/revista/v11/n4/ v11n4a11.htm.

20. Barros JFP, Alves KCAO, Filho AVD, Rodrigues JE, Neiva HC. Avaliação da capacidade funcional de idosos institucionalizados na cidade de Maceió - AL. RBPS Rev Bras Promoção Saúde. 2010;23(2);168-74. doi:10.5020/18061230.2010.p168.

21. Lovat A, Mayes R, McConnell D, Clemson L. Family caregivers' perceptions of hospital-based allied health services post-stroke: use of the measure of processes of care to investigate processes of care. Austr Occup Ther J. 2010;57:167-73. doi: 10.1111/j.1440-1630.2009.00828.x.

Recebido para publicação: 29/04/2014

Aceito para publicação: 15/12/2014 